REVIEW

\title{
How to prevent steroid induced osteoporosis
}

\section{P N Sambrook}

Ann Rheum Dis 2005;64:176-178. doi: 10.1136/ard.2003.018556

\begin{abstract}
The first choice for prevention of corticosteroid osteoporosis is a potent oral bisphosphonate-for example, alendronate or risedronate. Intravenous bisphosphonates should be considered for patients intolerant of the oral route. For patients receiving chronic low dose corticosteroids treatment with calcium and vitamin $D$ may prevent further bone loss. Use of parathyroid hormone is promising.
\end{abstract}

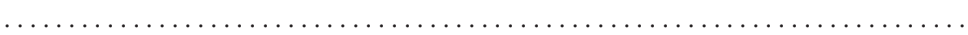

Correspondence to: Professor P N Sambrook, Royal North Shore Hospital, St Leonards, Sydney, Australia 2065; sambrook

@med.usyd.ed.au

Accepted 23 June 2004

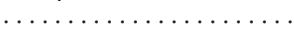

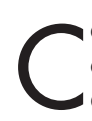

orticosteroids (CS) are widely used and effective agents for many inflammatory diseases, but rapid bone loss with subsequent fracture risk is a common problem associated with their long term use. A number of guidelines have been proposed by different groups for the treatment of steroid induced osteoporosis, ${ }^{1-3}$ although ever increasing evidence from trials in steroid osteoporosis means that such recommendations need constant updating. This review attempts to synthesise our current state of knowledge in a brief yet practical format for the physician in clinical practice. By its nature, it does not represent a comprehensive review of published reports, but rather a summary of pivotal articles relevant to clinical practice.

\section{DIAGNOSIS}

The earliest changes of CS induced osteoporosis are usually seen in sites of high trabecular bone content such as the lumbar spine and ribs, but bone loss can occur at any site. Assessment of fracture risk with CS is currently best performed by measurement of bone mineral density (BMD), preferably when subjects are starting CS treatment or soon after. Evidence that patients treated with CS fracture at a BMD threshold above that seen in postmenopausal osteoporosis remains unsubstantiated. ${ }^{4}$ However, because fracture risk with CS seems to rise when T scores fall below $-1.5^{5}$ and because it can be expected that in a person starting CS treatment BMD may drop by up to $10 \%$ or 1 standard deviation ( $\mathrm{T}$ score) in the first year, interventions may be appropriate at $\mathrm{T}$ score thresholds above the more conventional value of -2.5 usually applied in postmenopausal osteoporosis (fig 1). Profound changes in biochemical markers can also occur with CS, but their use for predicting patients likely to have a fracture remains unclear and there can be wide variation between patients.

\section{WHEN TO TREAT}

Because the most rapid bone loss often occurs in the first 12 months after starting CS, from a clinical point of view the optimal approach is primary prevention in patients starting CS who have not yet lost bone. However, treatment (or secondary prevention) in patients receiving long term CS, who will almost certainly have some significant degree of existing bone loss, will also reduce the fracture risk. So in CS induced osteoporosis perhaps the oxymoron applies, its never too early but equally its never too late to treat.

$$
\begin{aligned}
& \text { "It is never too early and never too late to } \\
& \text { treat" }
\end{aligned}
$$

\section{HOW TO TREAT}

Important approaches to avoiding CS induced osteoporosis include:

- Use of the lowest CS dose possible because fracture risk is dose dependent ${ }^{5}{ }^{6}$; generally, in most patients, doses below $5 \mathrm{mg} /$ day prednisone equivalent result in minimal bone loss, whereas doses above $10 \mathrm{mg} /$ day will result in significant bone loss. Between 5 and $10 \mathrm{mg} /$ day, some but not all patients will lose bone, and monitoring BMD may be useful.

- Use of agents that prevent or reverse bone loss. Agents that have been investigated by randomised trials, include calcium, both plain vitamin $\mathrm{D}$ and its active metabolites, calcitonin, hormone replacement treatment, bisphosphonates, and parathyroid hormone (PTH). ${ }^{7}$

\section{Bisphosphonates}

Bisphosphonates are currently the preferred treatment for CS osteoporosis and evidence comes from several recent trials. Most of these studies have examined their efficacy on BMD as the primary end point, although post hoc analyses consistently support an effect on fractures in the subgroup at highest risk-namely, postmenopausal women. The earliest trial to demonstrate efficacy used oral pamidronate, but studies now exist with all the commonly used bisphosphonates, including etidronate, alendronate, risedronate, and intravenous pamidronate.

The largest studies to date have been with oral alendronate and risedronate. The alendronate studies examined doses of $5 \mathrm{mg}$ and $10 \mathrm{mg}$ daily compared with a control group receiving prophylaxis with calcium/vitamin D and largely pooling the prevention and treatment arms.

Abbreviations: $B M D$, bone mineral density; $C S$, corticosteroid(s); HT, hormone therapy; PTH, parathyroid hormone 


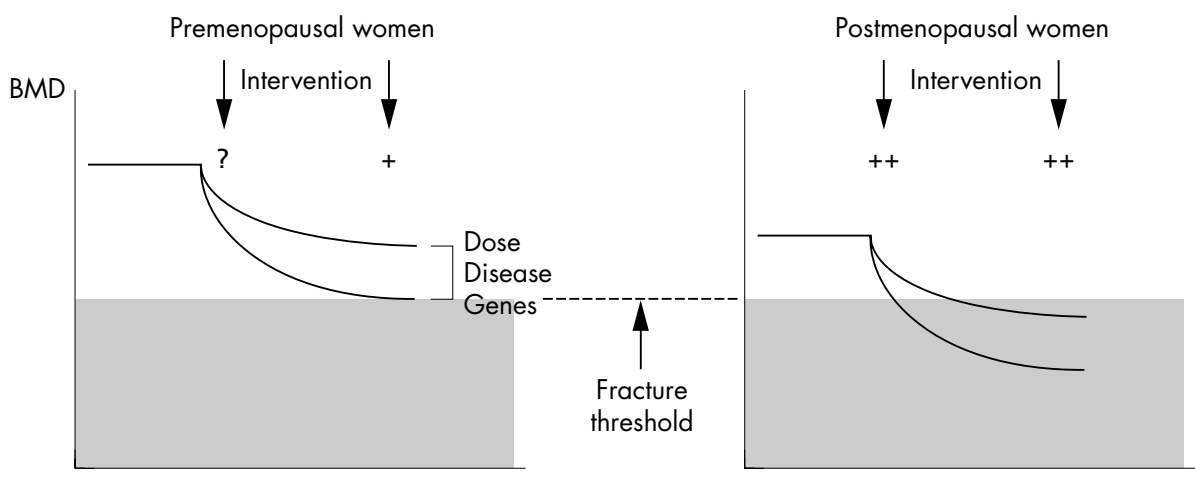

Figure 1 The degree of bone loss due to corticosteroids varies according to dose, underlying disease and, possibly, genetic factors. The case for intervention is strong (primary prevention) in postmenopausal women but is less clear in premenopausal women. As fracture risk is a function of time receiving corticosteroids, it is appropriate to consider secondary prevention in pre- and postmenopausal women receiving long term CS who have low BMD. Reproduced with permission from Sambrook PN, Corticosteroid osteoporosis: practical Fracture risk: time receiving steroids $\longrightarrow$ Res 2000;15:1645-9.

Over 12 months of follow up, the mean change in lumbar spine BMD in patients receiving CS for less than 4 months was $+3.0 \%$ for alendronate $10 \mathrm{mg} /$ day compared with $-1 \%$ in the control group. In those who had received chronic CS for more than 12 months, the increase with alendronate was $+2.8 \%$ but also $+0.2 \%$ for the control group. ${ }^{8}$ These latter data should be interpreted as suggesting that calcium/vitamin D can prevent further bone loss in patients receiving chronic low dose CS (secondary prevention) as discussed below. Although alendronate $5 \mathrm{mg}$ /day was approved for the treatment of CS osteoporosis on the basis of this study, it seems more prudent to use $10 \mathrm{mg} /$ day (or its weekly equivalent of $70 \mathrm{mg}$ ) in patients starting high dose corticosteroid treatment.

The risedronate trials were reported separately as prevention and treatment studies as well as pooled data.
Risedronate $5 \mathrm{mg} /$ day prevented spinal bone loss (+0.6\%) compared with calcium $500 \mathrm{mg} /$ day $(-2.8 \%)$ over 12 months in patients starting CS. In those receiving chronic CS, the calcium plus vitamin D control group showed a stable BMD over 12 months, whereas treatment with risedronate $5 \mathrm{mg}$ significantly increased lumbar spine $(+2.9 \%)$ and femoral neck $(+1.8 \%)$ BMD. Data from pooling of the two studies showed a greater than $50 \%$ reduction in new vertebral fractures at 1 year. ${ }^{9}$ Both the alendronate and risedronate trials, and indeed the etidronate trials, found a significant reduction in vertebral fracture incidence in postmenopausal women after 12 months with no fractures in premenopausal women.

\section{Calcium and vitamin D}

Extensive data on the use of calcium have been published, obtained from randomised trials in patients receiving CS
CLINICAL PRESENTATION
INVESTIGATION

MANAGEMENT

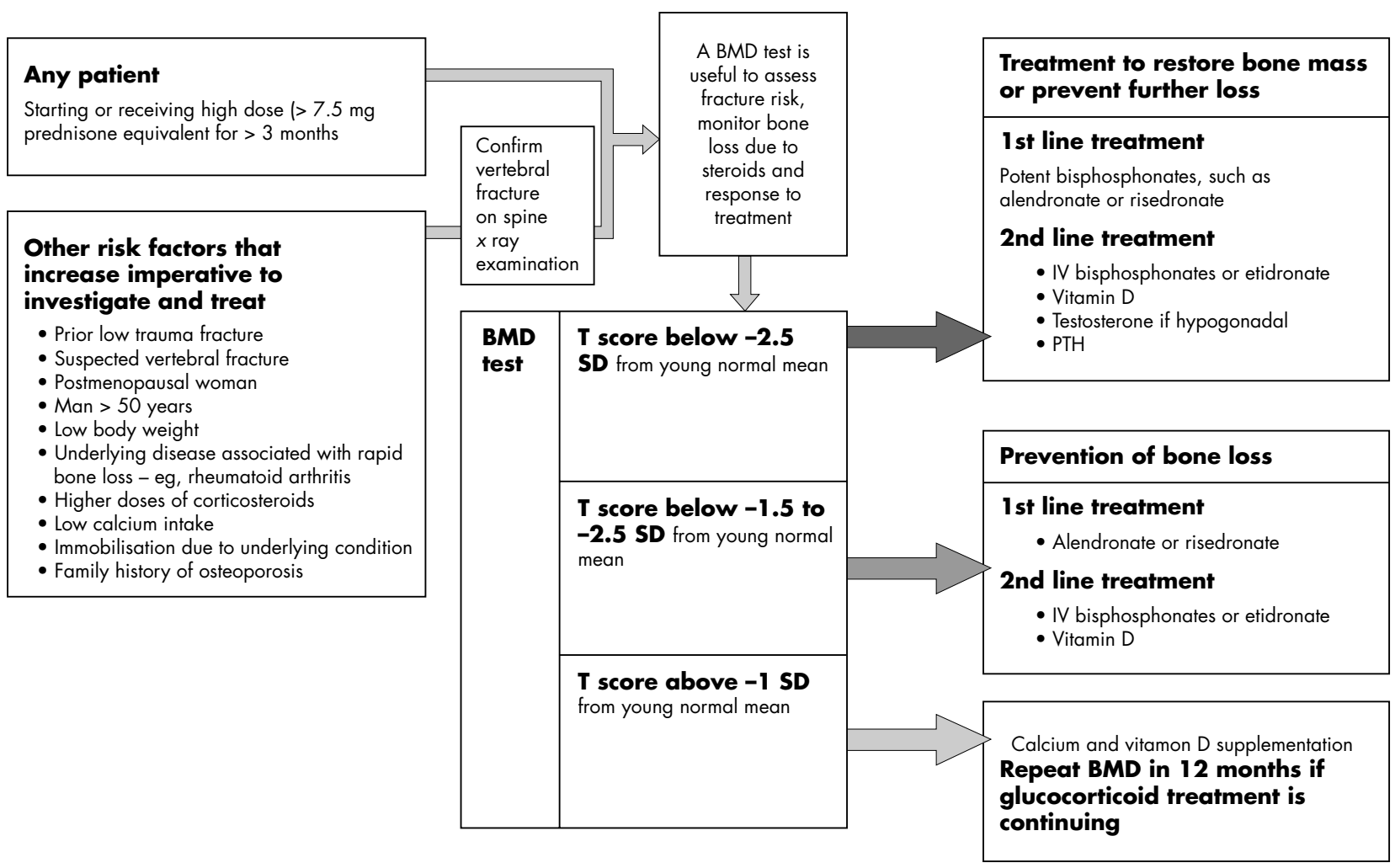

Figure 2 Management algorithm for glucocorticoid osteoporosis. 
where calcium has been used as the control or placebo treatment, indicating that considerable bone loss still occurs. These data suggest that calcium by itself is probably insufficient to prevent bone loss in patients starting CS, but may have some benefit as "treatment" in patients receiving chronic low dose CS. Overall in CS osteoporosis, calcium should probably be regarded largely as an adjunctive treatment.

However, calcium has also been used in combination with vitamin $\mathrm{D}$ and its metabolites as the control treatment in a number of randomised trials of other agents, and discerning the relative benefits of plain vitamin D from the combination is difficult. In the only study of spinal BMD to compare the combination of calcium plus vitamin D against true placebo in patients starting CS, bone loss at the lumbar spine showed a positive trend for the combination compared with placebo over 3 years, but the difference was not statistically significant. ${ }^{10}$ In contrast with this "prevention" setting, at least one "treatment" study in patients receiving chronic low dose CS found a significant benefit in patients treated with calcium/vitamin D compared with placebo. ${ }^{11}$

\section{"It remains controversial whether active metabolites are superior to plain vitamin D for the treatment of CS osteoporosis"}

Active vitamin D metabolites have quite distinct therapeutic effects compared with plain vitamin D and have been used in CS osteoporosis largely owing to their ability to enhance calcium absorption. The most commonly used formulations are calcitriol (1,25-dihydroxyvitamin D) and alfacalcidol ( $1 \alpha$ hydroxyvitamin D). Although there have been a number of positive trials, other studies have shown more variable results. Taken together, these studies suggest that active vitamin D metabolites probably have a modest effect in CS osteoporosis, ${ }^{12}$ but less than bisphosphonates. Whether plain vitamin $\mathrm{D}$ is less effective than active metabolites also remains unclear, with both positive and negative data having been published. ${ }^{13}$ Hypercalcaemia should be monitored if active vitamin D metabolites are employed and calcium supplementation should be avoided unless dietary calcium intake is low.

\section{Other treatments}

Hormone therapy (HT) is often recommended for CS treated patients, but the evidence supporting its use is limited to two small "treatment" trials of testosterone and oestrogen only. Recent evidence indicating that the risks of oestrogen treatment outweigh its benefits in older postmenopausal women means that agents such as bisphosphonates are preferred options. However, in CS treated men, serum testosterone levels are often substantially reduced, and in one study of 15 asthmatic men receiving chronic CS who were treated with testosterone $(250 \mathrm{mg} / \mathrm{month})$ or calcium a $5 \%$ increase in lumbar BMD over 12 months was observed. ${ }^{14}$

Calcitonin has also been studied in patients starting CS and receiving chronic CS, with variable results, and the clinical use of this treatment in CS osteoporosis remains in doubt.

It is of interest that there is such a large therapeutic benefit of the above antiresorptive agents in a disease state where effects on bone formation appear to be more important than effects on bone resorption. One agent, PTH, also appears to offer promise as an anabolic agent in CS osteoporosis. Positive effects have been reported with hPTH (1-34) in a randomised trial of HRT treated postmenopausal women receiving chronic CS. Over 12 months the patients treated with hPTH plus HT had significant increases in spinal bone mass $(+35 \%$ for lumbar spine quantitative computed tomography, $+11 \%$ by lumbar spine dual $x$ ray absorptiometry), with essentially no changes seen in the control group..$^{15}$ Follow up for an additional year after the hPTH (1-34) was discontinued showed further positive changes in the total hip and femoral neck bone mass. The study was too small to determine if hPTH (1-34) could reduce new vertebral fractures.

\section{SUMMARY}

Several large double blind controlled clinical trials in patients with CS osteoporosis have recently been published which provide new insights into its treatment. Based upon available evidence, the first choice for prevention would be a potent oral bisphosphonate such as alendronate or risedronate. In patients intolerant of oral bisphosphonates, intravenous bisphosphonates should be considered or a vitamin D metabolite (fig 2). Calcium alone appears unable to prevent rapid bone loss in patients starting CS, but calcium and vitamin $\mathrm{D}$ are appropriate adjunctive treatment. If an active vitamin D metabolite is used, calcium supplementation should be avoided unless dietary calcium intake is low. Testosterone should be considered in men if hypogonadism is present.

Most trial data are limited to $1-2$ years, but it is likely that prophylactic treatment needs to be continued while patients continue significant doses of CS treatment. In patients receiving chronic low dose $\mathrm{CS}$, treatment with calcium and vitamin D may be sufficient to prevent further bone loss, but if BMD is substantially reduced a bisphosphonate should be used or PTH considered, because fracture risk is a function of multiple factors, including the severity of low bone density as well as the duration of exposure to CS.

\section{REFERENCES}

1 Anonymous. Recommendations for the prevention and treatment of glucocorticoid induced osteoporosis, 2001 update. Arthritis Rheum 2001;44:1496-503.

2 Eastell R, Reid DM, Compston J, Cooper C, Fogelman I, Francis RM, et al. A UK consensus group on management of glucocorticoid induced osteoporosis: an update. J Intern Med 1998;244:271-92.

3 Anonymous. Guidelines on the prevention and treatment of glucocorticoid induced osteoporosis by the Bone and Tooth Society, National Osteoporosis Society and Royal College of Physicians. www.rcplondon.ac.uk/pubs/books/ glucocorticoid/index.asp (accessed 23 November 2004).

4 Selby PL, Halsey JP, Adams KRH, Klimiuk P, Knight SM, Pai B, et al. Corticosteroids do not alter the threshold for vertebral fractures. J Bone Miner Res 2000;15:952-6.

5 Van Staa TP, Laan RF, Barton IP, Cohen S, Reid DM, Cooper C. Bone density threshold and other predictors of vertebral fracture in patients receiving oral glucocorticoids therapy. Arthritis Rheum 2003;48:3224-9.

6 Van Staa TP, Leufkens HGM, Abenhaim L, Zhang B, Cooper C. Use of oral glucocorticoids and risk of fractures. J Bone Miner Res 2000;15:993-1000.

7 Amin S, Lavalley MP, Simms RW, Felson DT. The comparative efficacy of drug therapies used for the management of corticosteroid induced osteoporosis: a meta regression. J Bone Miner Res 2002;17:1512-26.

8 Saag KG, Emkey R, Schnitzer TJ, Brown JP, Hawkins F, Goemaere S, et al. Alendronate for the prevention and treatment of glucocorticoid induced osteoporosis. N Engl J Med 1998;339:292-9.

9 Wallach S, Cohen S, Reid DM, Hughes RA, Hosking DJ, Laan RF, et al. Effects of risedronate treatment on bone density and vertebral fracture in patients on corticosteroid therapy. Calcif Tissue Inter 2000;67:277-85.

10 Adachi J, Bensen W, Bianchi F, Cividino A, Pillersdorf S, Sebaldt RJ, et al. Vitamin $D$ and calcium in the prevention of corticosteroid-induced osteoporosis: a three year follow up study. J Rheumatol 1996;23:995-1000.

11 Buckley LM, Leib ES, Cartularo KS, Vacek PM, Cooper SM. Calcium and vitamin D3 supplementation prevents bone loss in the spine secondary to low dose corticosteroids in patients with rheumatoid arthritis. Ann Intern Med 1996;125:961-8.

12 Richy F, Ethgen O, Bruyere O, Reginster JY. Efficacy of alphacalcidol and calcitriol in primary and corticosteroid induced osteoporosis: a meta-analysis of their effects on bone density and fracture rate. Osteoporos Int 2004; 15:301-10.

13 Sambrook PN, Kotowicz M, Nash P, Styles CB, Naganathan V, HendersonBriffa KN, et al. Prevention and treatment of glucocorticoid induced osteoporosis: a comparison of calcitriol, vitamin D plus calcium and alendronate plus calcium. J Bone Miner Res 2003;18:919-24.

14 Reid IR, Wattie DJ, Evans MC, Stapleton JP. Testosterone therapy in glucocorticoid-treated men. Arch Int Med 1996;156:1 173-7.

15 Lane NE, Sanchez S, Modin GW, Genant HK, Pierini E, Arnaud CD. Parathyroid hormone treatment can reverse corticosteroid-induced osteoporosis. J Clin Invest 1998;102:1627-33. 